\title{
Mars Ice House: Using the physics of phase change in 3D printing a habitat with $\mathrm{H}_{2} \mathrm{O}$
}

\author{
Michael Morris ${ }^{1}$, Christina Ciardullo², Kelsey Lents ${ }^{3}$, Jeffrey Montes ${ }^{4}$, Melodie Yashar ${ }^{5}$ \\ SEArch (Space Exploration Architecture), New York, NY \\ and \\ Ostap Rudakevych ${ }^{6}$, Masa Sono $^{7}$, Yuko Sono ${ }^{8}$ \\ Clouds Architecture Office, New York, NY
}

\begin{abstract}
Mars Ice House was the first place winner of NASA's 2015 Centennial Challenge to 3D print a habitat for Mars employing indigenous material resources. Unlike most traditional design concepts making use of Martian regolith, Mars Ice House makes use of subsurface ice in the construction of a full 3D printed habitat made out of solid $\mathrm{H}_{2} \mathrm{O}$. Citing new evidence of the potential hazards of perchlorates in the Martian soil, working within NASA's "follow the water" approach to exploration, and stemming from a human centered design approach wanting to connect largely interior habitats to the light and vistas of the surrounding landscape for human psychological wellbeing, $\mathrm{H}_{2} \mathrm{O}$ serves as a radiation barrier, absorbing shorter wavelength radiation, while allowing light through in the visible spectrum. The resultant is a $1000 \mathrm{ft}^{2}\left(92 \mathrm{~m}^{2}\right)$ translucent vertical habitat with a maximum of surface visibility allowing visible light into the interior of the habitat. The design covers all potential aspects of construction from water collection, concept of operations, and semi-autonomous robotic 3D printing, all which exploit the manipulation of pressure and temperature to build with phase change avoiding more laborious, high energy consuming building techniques and with potentially toxic materials such regolith. Investigating several potential methods, Mars Ice House was able to demonstrate scaled 3D printing of ice as well as use small-scale robotic technologies capable of building large-scale structures. Furthermore the design of Mars Ice House proposes spatial and scalable approaches to building with solid $\mathrm{H}_{2} \mathrm{O}$ as a primary building material that support human health and wellbeing.
\end{abstract}

\section{Introduction}

$\mathrm{T}$ he Mars Ice House project is a concept design approach for additive manufacturing of a human habitat with insitu materials on Mars. The project was designed in response to a call from NASA and America Makes in 2015 to present proposals for NASA's Centennial Challenge. Calling for a design and method for constructing a habitat no more than $1000 \mathrm{ft}^{2}\left(92 \mathrm{~m}^{2}\right)$ to last a 500 day surface mission for a crew of 4 astronauts, the goal of the competition was to elicit design ideas for an autonomously or semi-autonomously processes for large scale additive manufacturing. The Mars Ice House, consisting of an interdisciplinary group of subject matter experts, lead by a team of architects and designers, was a holistic response to the idea of a habitat meant for human occupation using mostly in-situ materials (incorporating the mechanical lander at its core). The use of water as the primary construction material was the basis of a project for both human psychological as well as radiation and construction factors.

\footnotetext{
${ }^{1}$ Fellow / NASA X-Hab Visiting Professor of Architecture, Pratt Institute, Brooklyn, NY.

${ }^{2}$ Ann Kalla Fellow, Assistant Professor, Carnegie Mellon University School of Architecture, Pittsburgh, PA.

${ }^{3}$ Designer, SEArch, New York, NY.

${ }^{4}$ Designer, SEArch, New York, NY.

${ }^{5}$ Designer, SEArch, New York, NY.

${ }^{6}$ Adjunct Professor, Pratt Institute, Partner, CloudsAO, New York, NY.

${ }^{7}$ Partner, CloudsAO, New York, NY.

${ }^{8}$ Designer, CloudsAO,New York, NY.
} 


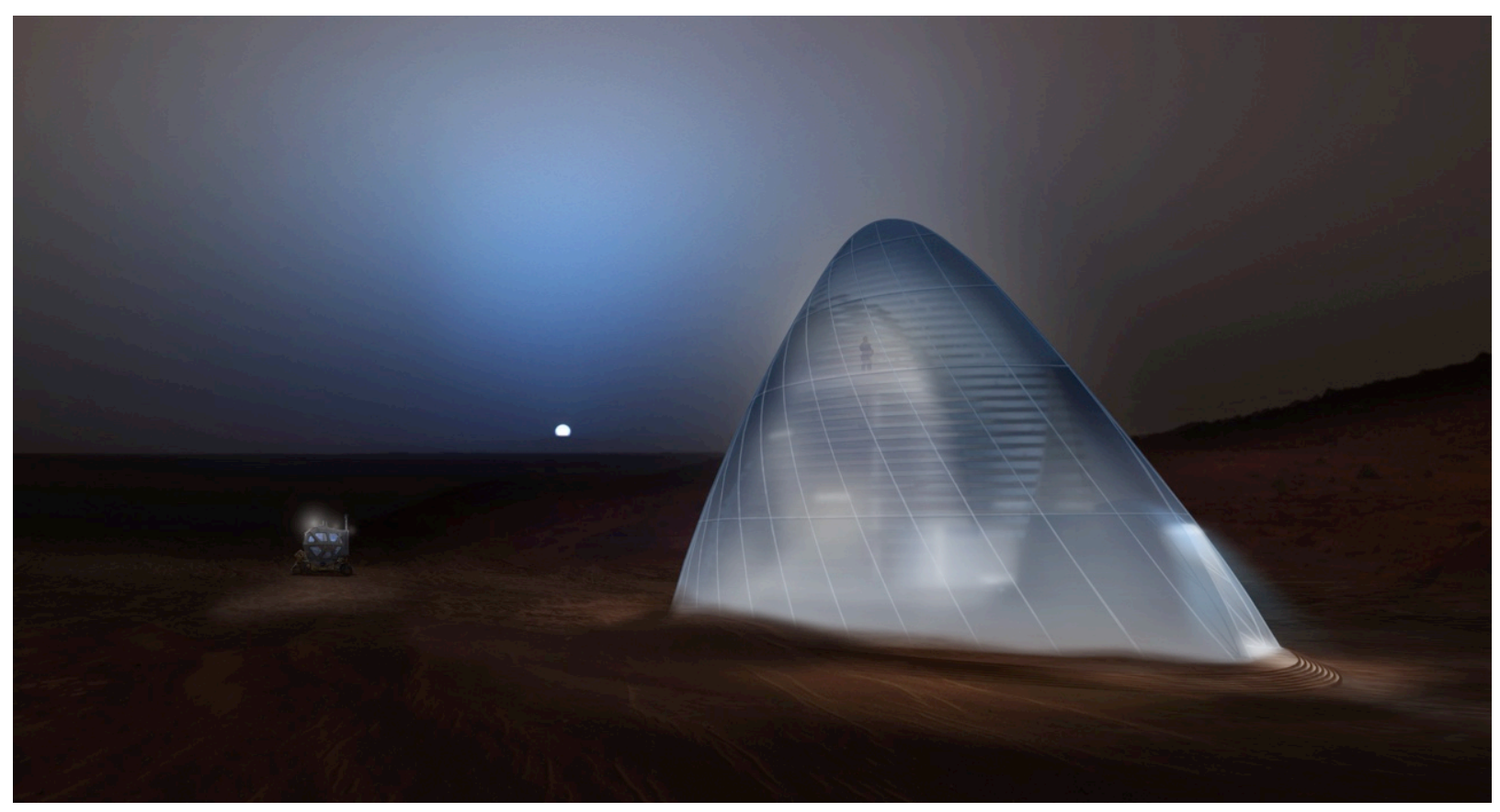

Figure 1. Exterior view of the translucent habitat.

\section{Motivations for Construction with $\mathrm{H}_{2} \mathrm{O}$}

Among the primary concerns for long duration manned martian exploration is the health of the crew, including reduction of exposure to radiation on the surface as well as the psychological health of spending a 500 day surface mission and two 180 day transits wholly inside an enclosure. ${ }^{17}$ In designing a habitat for human Mars mission, the concern is not entirely based on structural optimization, nor in environmental conditioning, but also in human experience. After establishing a baseline for the essential human needs, and requirements of the habitat to be made from in-situ materials that would provide radiation protection, thermal comfort, volumes for human habitation, and creating transcendent spaces for celebrating our collective aspiration to pioneer and explore Mars. Based on these requirements and the availability of the material, $\mathrm{H}_{2} \mathrm{O}$ was selected as a possible candidate construction material.

\section{A. Defining Building Envelope Function}

When we consider the notion of shelter here on Earth, depending on the site, there are a number of factors that temper the interior environmental quality to human comfort ranges including air velocity, pressure, temperature, humidity, and in the case of extraterrestrial habitats, radiation protection. It requires one or multiple boundaries between an exterior and an interior condition or gradient thereof.

In considering a shelter on Mars, the pressure boundary becomes the primary space-defining element. In the consideration of an in-situ material structure, a survey of concepts to date rely on the presence of a pressure membrane sent from Earth to act as a supplement to an in-situ structure. To construct a pressure-vessel out of in-situ materials would require a concrete-like solution to have extreme thickness, or a more metallic or tensile solution, which is complex to produce. Assuming that the pressure would be handled then by a supplemental structure questions the functional role of the in-situ material as several concepts for deployable or expandable structures address other environmental factors within the concept of the skin of the structure itself. ${ }^{9}$ However, in calling for insitu construction there must be some kind of optimal balance between a pressure boundary and the supplemental insitu materials, and so we assume the primary environmental or shelter functions of the in-situ material to be radiation protection and temperature insulation, assuming wind force and precipitation to be of lesser concern due to the thin atmosphere.

There are a number of ways to approach the problem of using a hybrid pressure envelope with materials providing these other environmental functions. Many approaches use an interior pressurized area, often inflatable, onto of which is constructed secondary environmental layers using regolith. This approach protects an inner pressure 
but limits spatial functions on the interior. There is a consistent sense of enclosure and interiority inherent to this method of construction because the occupant is always exposed to the internal pressure volume.

The Mars Ice House explored the idea of placing the pressure boundary on the exterior due to the necessity of keeping water ice from sublimating into the atmosphere. This restructuring of the pressure envelope allowed for a number of different spatial configurations with the in-situ printed materials. By creating an overall pressure envelope into which we can build multiple layers of structures, it allowed for the freedom to create more and varied functional spaces on the interior. Using one or more exterior pressure envelopes allows us to create several interior spaces with in-situ material and also to create a sense of outside by being able to pass through multiple enclosures while still within the pressure boundary.

\section{B. The Risks of Regolith}

Many architectural concepts for Mars and other planetary bodies assume a kind of "bunker mentality," assuming underground construction, or habitation covered with multiple layers of regolith, the human experience is buried to protect inhabitants from radiation levels at the surface. Radiation levels at the surface has been estimated at 0.64 $\mathrm{mSv} /$ day $\left(230 \mathrm{mSv} /\right.$ year) from cosmic radiation (GCR) and $0.025 \mathrm{mSv}$ from solar events (SEP). ${ }^{20}$ Annual exposure for humans on the ISS had been set to no more than $200 \mathrm{mSv} / \mathrm{year} .^{19}$

It is believed that a regolith covering of $50 \mathrm{~cm}$ thick (at a density of $1.5 \mathrm{~g} / \mathrm{cm}^{3}$ ) ${ }^{13}$ could provide the necessary protection, and as the most visible and prevalent material on the surface it seems to be the material of choice.

However, recent studies indicate the possible presence of perchlorates $\left(\mathrm{ClO}_{4}^{-}\right)$in the Martian soil, a chemical toxic to human humans impairing the proper function of the thyroid by inhibiting the uptake of iodine ions. ${ }^{5}$ The use of this material in construction could cause potential hazards if not completely isolated from the interior environment, making it all the more reasonable to search for an alternative material when it comes to human habitation.

\section{Radiation}

As a material with high hydrogen content, $\mathrm{H}_{2} \mathrm{O}$ has often cited as a material capable of providing shielding in the high radiation environment. Results indicate that hydrogenous materials of low atomic weight are substantially superior to heavy metals for energetic ion shielding. ${ }^{13}$

From Figure 2, one could show that a water thickness of $20 \mathrm{~cm}$ would provide proper shielding against GCR which is of main concern. This thickness, if distributed across multiple layers of a habitat would be enough to provide a significant storm shelter. The Mars Ice House distributes ice to $10 \mathrm{~cm}$ thickness of ice on an outer layer and $10 \mathrm{~cm}$ thickness on an inner layer.

The difference between ice and liquid water for radiation protection requires further study. The Mars Ice House calls for the use of an ice re-surfacer for both the clarity and visibility of the ice as well as to increase density.

As one of, if not the primary driver, in the design of exterior sheltering for human missions, the ability for water to theoretically outperform regolith makes it a particularly interesting material consideration.

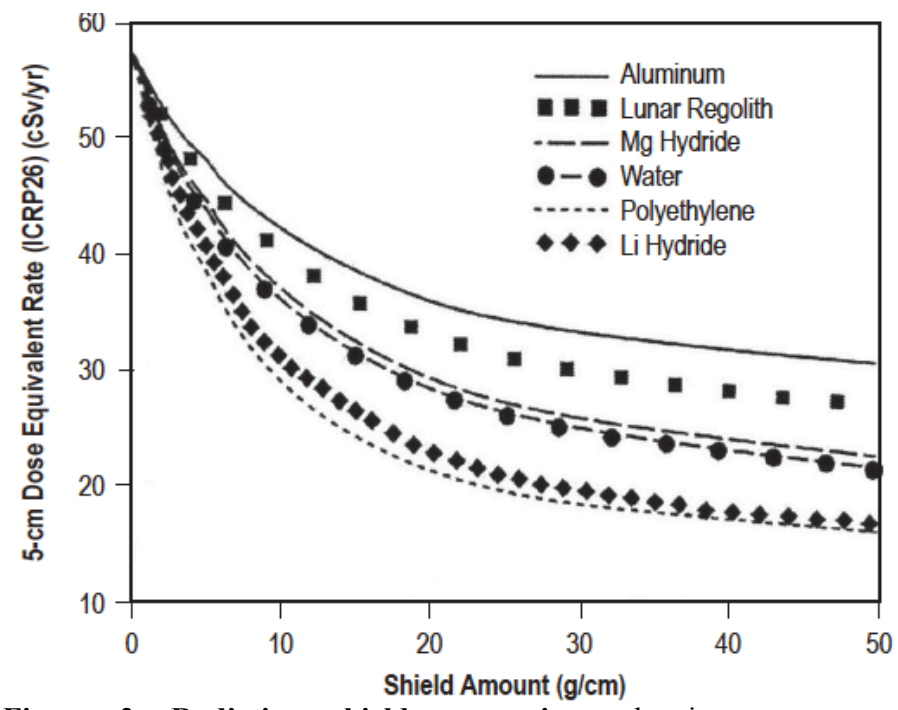

Figure 2. Radiation shield comparison showing necessary thickness of water versus lunar regolith for shielding. (Simonsen, 1991)

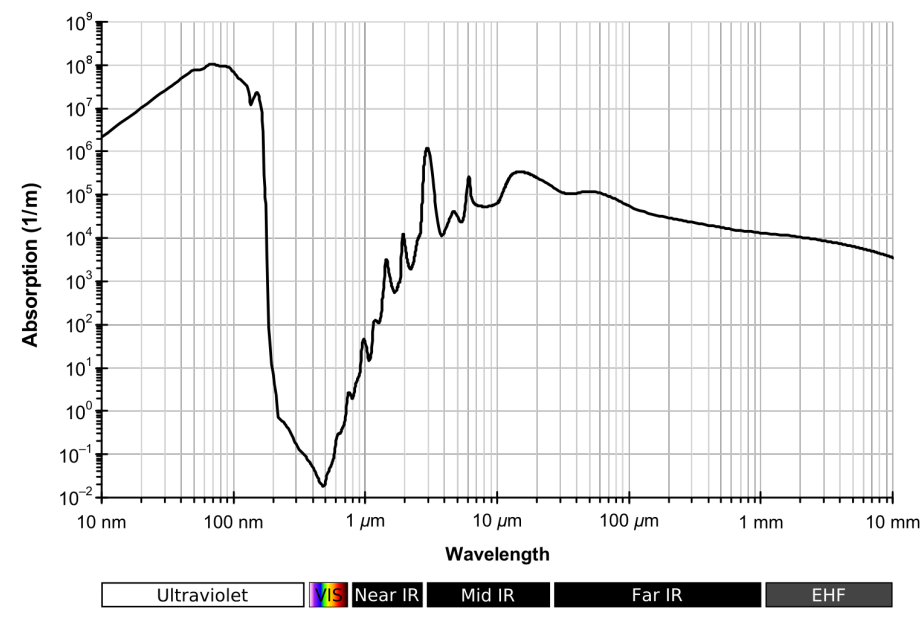

Figure 3. Absorption spectrum of liquid water showing absorption in the UV and transmission in the visible spectrum. (Warren, 2006)

3

International Conference on Environmental Systems 


\section{Visible Light}

The design emerged from a response to potential human needs to bring light to the interior and to create visual connections to the landscape beyond, allowing the mind as well as the body to thrive. The importance of windows on spacecraft for psychological and practical purposes has been studied even though the integration of windows in spacecraft introduced possible locations of failure. There still appears to be a psychological benefit between being able to see and experience the space outside from the interior. ${ }^{7}$

The effects of natural light as well have been widely studied in building occupancy as being beneficial to human mental health. ${ }^{4}$ While many have experimented with what could potentially be artificial replacements for sunlight, and exposure to natural light through fiber optics, artificial substitutes do not hold the same circadian variance or ability to balance a crew's mental and physical health as does experiencing the sun's actual and unmediated daily cycles.

Just as water absorbs higher energy wavelengths, it transmits light in the visible spectrum. The transmittance levels vary based on the fabrication process, yet even domes made with snow blowing and contain opaque additives have shown some light transmittance. Experimentation with different techniques for the deposition of ice were explored which included methods of resurfacing ice to remove air bubbles that may effect light transmission.

In addition to letting sunlight in, the architecture celebrates the presence of a human habitat as a beacon of light on the Martian surface creating a landmark for human habitation that would create an inspirational vision for those remaining home on Earth.

\section{E. Availability / Necessity}

Requirements for any manned mission in more remote locations include the presence of in-situ water, something which new discoveries have proven to be perhaps more plentiful in our solar system and the broader universe than once imagined. Recent research on the Moon, Mars, Pluto, Europa, Ceres, etc. have all indicated the presence of $\mathrm{H}_{2} \mathrm{O}$ in some form, leading to the belief that it is in fact quite common. ${ }^{11}$ NASA has, for targeting it's Martian surface research also adopted a "follow the water" approach as these areas will be of high scientific value. ${ }^{8}$ As we continue to propose missions that might extend to these areas, perhaps in a long term future to human exploration, it's availability a common material, and one we already require to survive, makes it an interesting option to explore as a potential building material.

\section{F. Human Psychology and Habitability}

In addition to the environmental requirements, there are a number of requirements that conform to the functionality of performing certain tasks require the creation of "space" in which to act: a need to organize and define space of operation with boundaries. On top of these, and related to them, are human psychological and social considerations, which are often considered secondary to environmental conditioning. If for a moment, we were to equate these requirements, often for the benefit of optimal crew performance, we offer ourselves the opportunity to challenge our conceptions of what an extraterrestrial habitat should be, one that is more than shelter alone. Architectural and design features based on their formal, organizational, and material properties directly affect behavioral issues on long term interior isolation including: sleep, exercise, hygiene, food preparation, group interaction, and privacy and personal space, among others. ${ }^{18}$

Mars Ice House used water as primarily a material in order to experiment with not only the environmental, but human psychological requirements of providing visual stimuli, changing imagery, and landscape contemplation through visual connection to the exterior. ${ }^{18}$ The methods of construction offered opportunities for spatial configuration that would provide a type of outdoor relief while still inside a pressurized habitat. These new possibilities were only explored as a result of human considerations in parallel with environmental ones. It is imperative that in the consideration of manned missions that a more holistic or inclusive set of requirements be evaluated as they pertain to the mission objective. The presence of humans in space potentially has quite more objectives than simply the return of science content, and these objectives must be explored and understood thoroughly before the selection of technical criteria. 


\section{Ice Construction}

Working with water on Mars requires manipulation through phase change. The exposure of solid $\mathrm{H}_{2} \mathrm{O}$ to the Martian atmosphere would result in its immediate sublimation as the Mars surface pressure of 610 pa is below the triple point of $\mathrm{H}_{2} \mathrm{O}$. Relying more on the physics of phase change than on potentially laborious mining and laying techniques we sought a way to extract the subsurface solid, to collect it as a gas thereby purifying it, accumulate or print it as a liquid, and maintain it as a solid.

\section{A. Precedents in Earth Construction}

Construction with ice on Earth is not without precedent. In addition to long standing cultural practices in arctic climates using thick snow blocks for insulation, modern examples of structures include Pykrete, a composite material developed in 1942 using ice reinforced with wood pulp, much like reinforced concrete, and with a similar strength. Field experiments using ice domes to span 20-30 meters have been

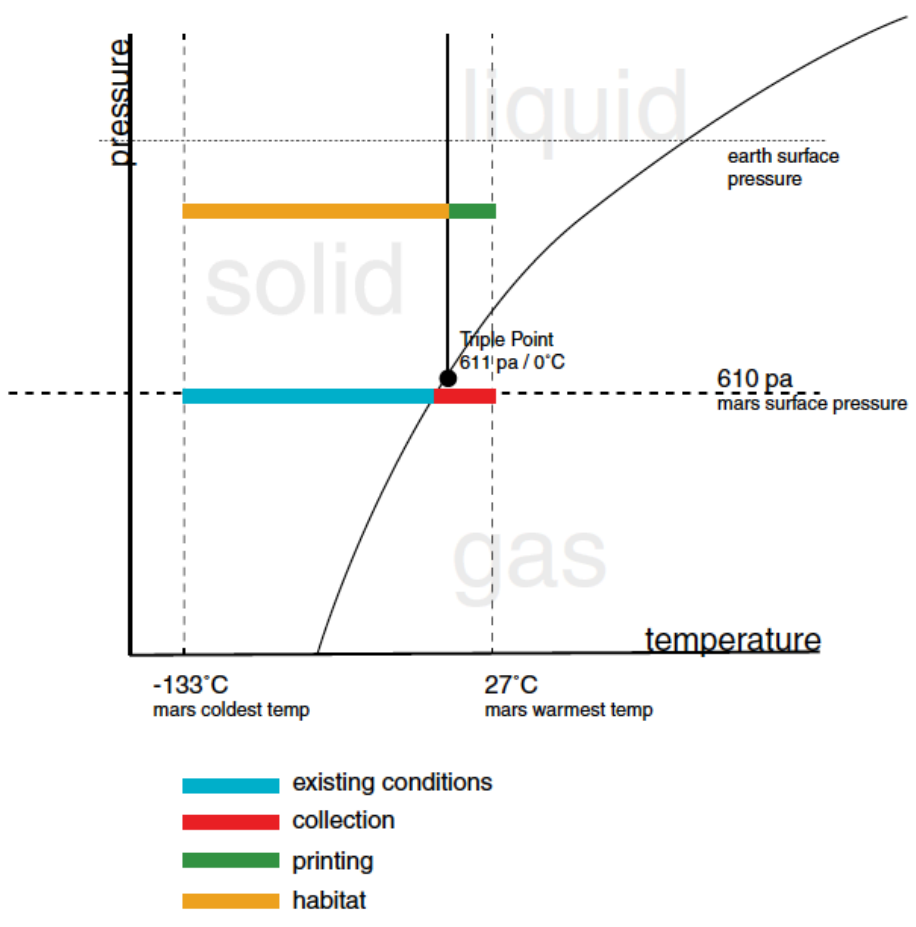
carried out in Japan since 1999, and Pykrete structures larger than $30 \mathrm{~m}$ were constructed in the Netherlands. In the mid $20^{\text {th }}$ century, Swiss architect Heinz Isler famously constructed thin shell structures using ice and fabric, experiments that have been repeated in universities over many years.

Perhaps a common factor in these precedent examples is the temporality of structures that exist in only persistent climates. Consistently cold temperatures on the surface of Mars promise a more permanent solution. Ironically, or perhaps not surprisingly, adaptations of earth precedents were present in the conceptualization for the construction of an ice structure on Mars, including additive silica fibrous reinforcement (potentially drawn from surface minerals or the recycling of lander parachutes) which was the technique used in pykrete (using timber fiber reinforcement), and potential insulation techniques adapted from igloo snow construction.

\section{B. Precedents in Space Applications}

Though referred to in extensive publications for its radiation shielding abilities, ${ }^{12,13}$ the idea of using water as a construction material has only begun to be explored for space missions, perhaps due to the relatively recent discovery of water on many other solar system bodies. One design of note where water was used was in the design for NASA's TransHab module, which called for water walls on the interior core, which doubled as utility services as well as radiation protection. ${ }^{9}$ One concept for a water regolith slurry infill between deployable membranes was recently selected as a winner in the 2015 Innocentive Challenge for Space Pioneering: Achieving Earth Independence. New ideas certainly will proliferate following more feasibility testing.

\section{Ice Harvesting/Collection}

To extract filtered $\mathrm{H}_{2} \mathrm{O}$ from the subsurface, depending on the depth of the ice table, which in many cases is believed to be from $20 \mathrm{~cm}$ to $1 \mathrm{~m}$ below the surface, ${ }^{6}$ solid ice could be exposed, cut, and captured. Heating a contained block of Martian ice with solar radiation while still in low atmospheric conditions could allow for the collection of water vapor into storage compartments as well as naturally filtering the pure liquid water form any remaining minerals or contaminants that may disrupt storage or viability of the printing systems. 


\section{Ice Printing}

Additively creating a structure with ice requires both the tools for moving and the tools for depositing material.

Traditional 3D printers consist of three-dimensional axes of movement and appropriately designed deposition tool (print head) for a particular material. The ability to control the three-dimensional axes has kept 3D printing until now quite contained within the defined boundaries of access. Robotic arms have increased the axis of movement, but still the construction of objects remains of a scale within the range of the arm of the robot. Printing large scale structures requires either a much larger range of axis, or the ability for the axis (the robotic arm or print head) to be moved itself to cover a larger area.

In addition, the design of the print head itself would vary based on materials.

The design of these tools in tandem has a significant impact on the overall formal and structural possibilities of the habitat.

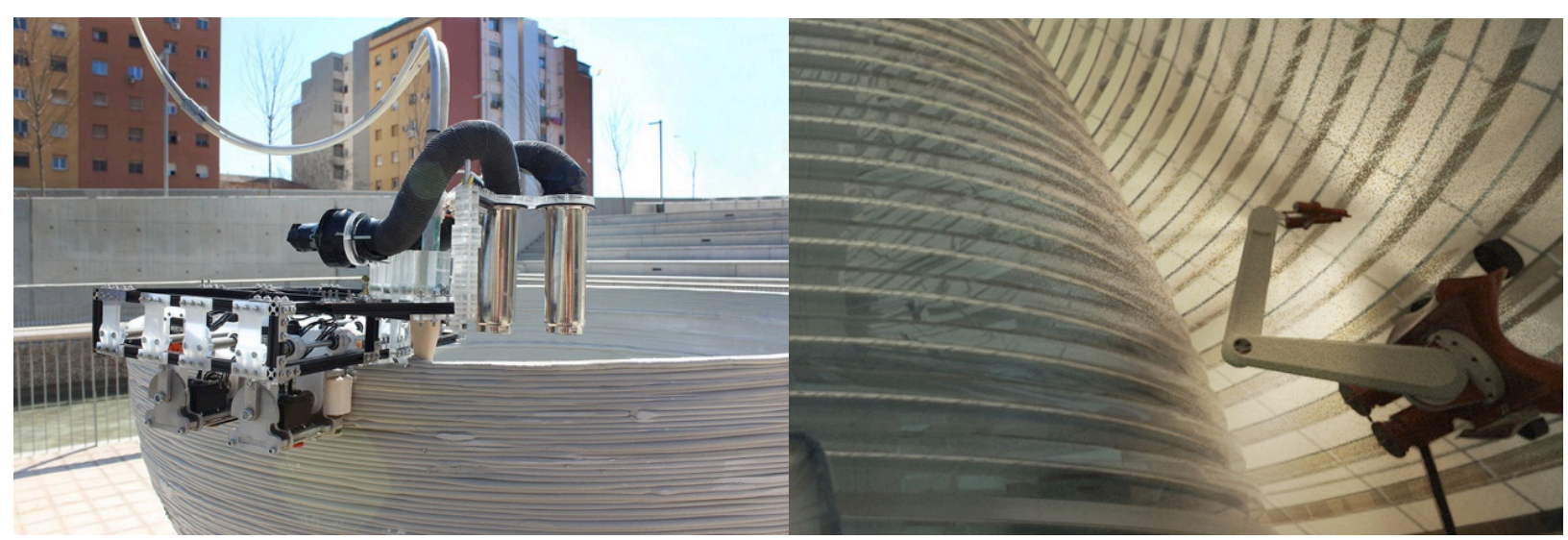

Figure 5. (Left) "Minibuilders" construct and simultaneously climb a wall at the IAAC was the basis for the (Right) Mars Ice House concept image of a robot capable of scaling the wall it has already constructed.

\section{1) Mobility}

Mobile printing robots are based on the concept of "minibuilders," a design investigation done at the Institute for Advanced Architecture at Catalonia (IAAC) with whom we collaborated on this project. A number of small robots, would be connected mechanically to water storage. These small robotic movers are capable of both depositing material as well as climbing the walls of that material once deposited through the use of vacuum gripping. By gripping onto the sides of a layered wall surface they can continue to climb and deposit material as they go. These gripping mechanisms are being designed as well to hold onto ceiling or roof constructions, and so eliminating the need for support structures typically necessary in 3D printing.

There are similar concepts in earth construction. Musgum mud huts, where footholds are incorporated into the surface of the hut as a built-in scaffold to allow workers access to complete the upper portions. This directly inspired the spiral self-printed rails that allow the rovers access to continue printing the shell

\section{2) Deposition Mechanism}

To achieve structural and thermal properties, we called for a printing head capable of depositing

1) water

2) fiber reinforcement

3) a conceptual tool for the re-surfacing of the ice layer through instant melting and re-freezing to achieve greater clarity or transparency in the ice

4) an aerogel insulation layer

We focused primarily on the deposition of water as the primary objective.

Several methods were considered in the additive construction of ice through phase change. Two were seriously considered. One concept was a method to sublimate water vapor into a pressurized interior on the undersurface of a pressure membrane. Due to the unpredictable nature of this method, a more traditional additive procedure was pursued but further research is required to test the viability of such of concept. This concept, while additive in nature, requiring no precise robotics, was potentially imprecise and untested.

The alternative was a more traditional means of layer-by-layer gravitational deposition of material, again, within a pressurized volume. This membrane, precision manufactured on Earth, is critical protection for the future ice shell, preventing any printed ice from sublimating into the atmosphere. 
A heated supply of liquid water would be fed through insulated hoses to the mobile "printer heads." A low-volume, close-range nozzle would ensure that any water that freezes mid trajectory melts and refreeze instantaneously via the energy of its impact (a contact weld).

\section{3) Additives}

Precedent earth ice construction like Pykrete have benefited from the addition of fibers like wood pulp for the reinforcement of the ice shell. Thinking of an analogous potentially translucent reinforcement material, a fibrous clear silica additive (flat-packed in the lander) could provide the ice form with greater tensile strength, ${ }^{1}$ calculated to bolster the strength of ice to the order of 3 times. While ice has been shown to possess tensile properties $(\sim 2-3 \mathrm{MPa})^{10}$ that are, in fact, superior to materials such as brick (2.8 MPa) and granite $(4.8 \mathrm{MPa})$, the fibrous reinforcement ensures the longevity and integrity of the structure.

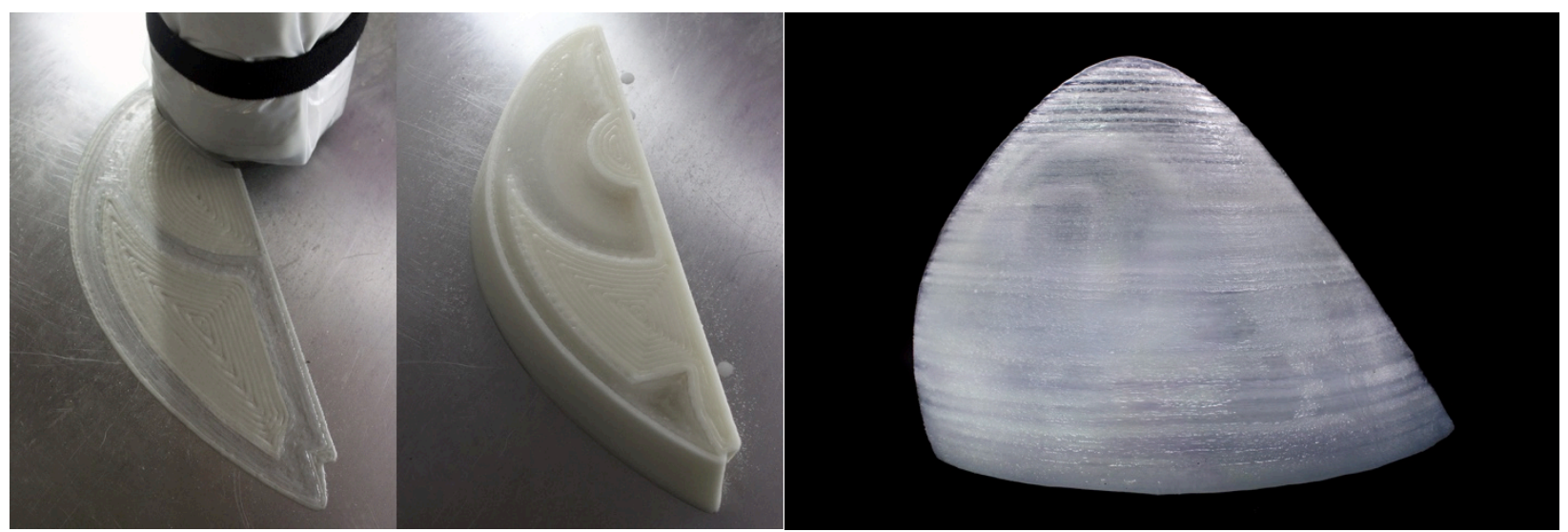

Figure 6A. (Left) Additive deposition of water ice and brine support structure conducted for this project in freezer facilities with an insulated robotic arm at McGill University, Montreal. (Right) final 3D printed ice structure after the melting of the brine support material.

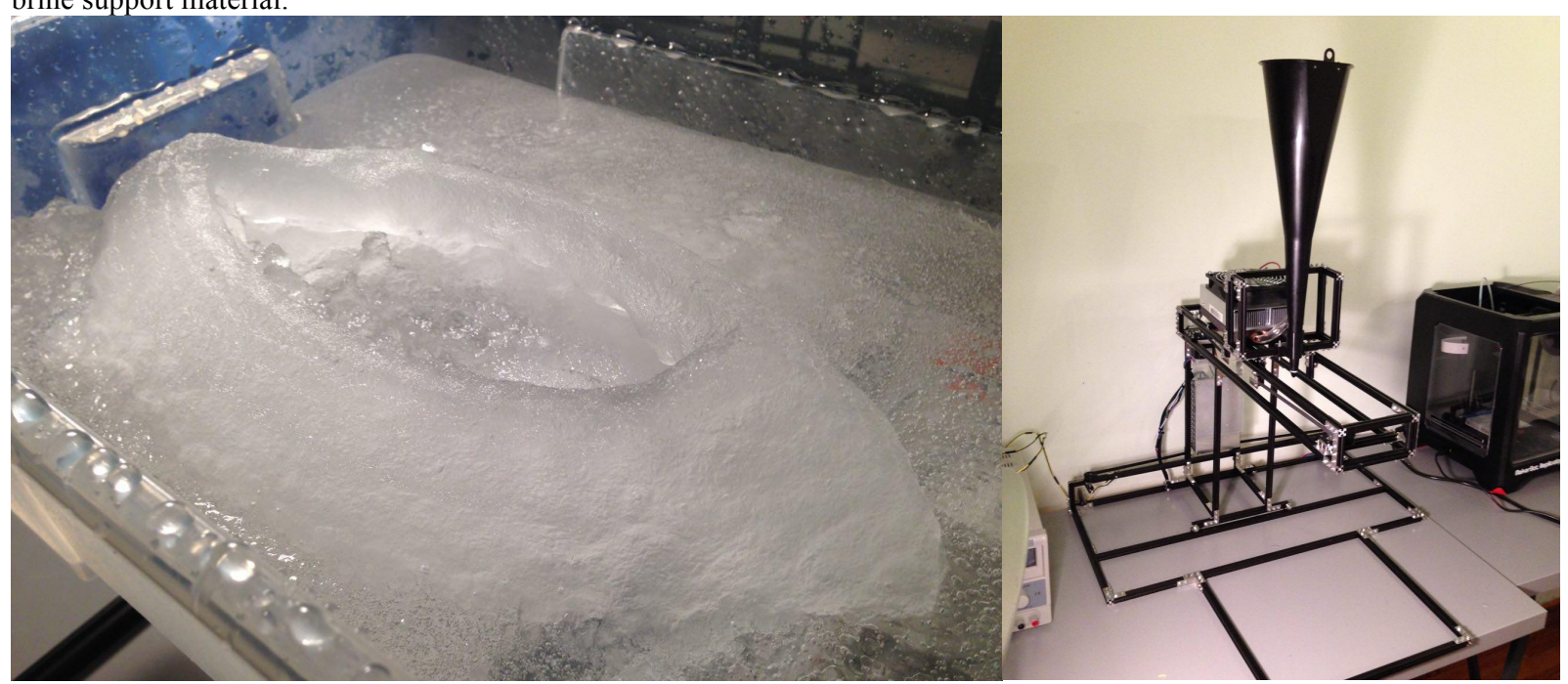

Figure 6B. (Left) Additive deposition of water ice, constructed by Petr Novikov for SEArc. (Right) water ice deposition mechanism showing movement in multiple axes.

\section{E. Earth Analogue Testing}

Tests in the 3D printing of ice were performed on Earth. The Mars Ice House team in collaboration with McGill University in Montreal printed a prototype within a freezer environment. In this case, a traditional robotic arm was used and frozen brine was substituted as support structure, which melts at a lower temperature than the pure ice. Through the use of mobile robotics, we anticipate that no such support structure would be required in full-scale construction. Further testing was conducted using larger scale robotics outside the freezer environment with some success. 


\section{Concept of Operations}

Translating the above methods into a concept of operations for the autonomous or semi-autonomous deployment of a habitat may follow a rough sequence as follows:

\section{A. Entry Descent and Landing (EDL)}

At the center of construction is a single lander, sized for the currently available payload of a Space X Falcon Heavy and NASA's Space Launch System (SLS), which carries with it a deployable pressure membrane, Environmental Control and Life Support Systems (ECLSS), ice collection and harvesting robots as well as water storage and interior ice printing robots.

\section{B. Ice Harvesting and Foundation}

The first phase of in-situ resource utilization (ISRU) is exterior in focus, mining the surrounding landscape for water and creating a foundation in which to ground the lander. Robots engineered specifically for both sintering and ice harvesting drop from the lander's base hatch, deployed to mine subsurface ice and build a new foundation. Once released through the hatch, they remain exterior, thereby avoiding potential contamination with the interior. The double acting machine would use its ability to shovel and heat regolith both to collect Martian dust and extract water and other volatiles, while laser technology serves to both sinter waste regolith as well as cut solid ice below the ice table. Ice is sublimated and collected within a reservoir for use in future printing as well as greenhouse maintenance.

\section{Pressure Membrane Deployment and Printing}

Prior to the printing of any ice, a pressurized interior must be created in which $\mathrm{H}_{2} \mathrm{O}$ will remain solid. It is therefore conceived that the lander would inflate a transparent membrane serving as a pressure vessel. Ethylene tetrafluoroethylene (ETFE) is considered as its high tensile strength capacity is meant to function over large temperature ranges. Reinforced along biased stress lines with Dyneema strands, this inflatable transparent exterior must be deployed before any interior construction can take place.

Once deployed, ice-printing robots are released from the lander base and begin the layer-by-layer deposition of ice within and alongside the pressurized membrane. Following the deposition of ice, an interior layer of insulating material would also be printed.

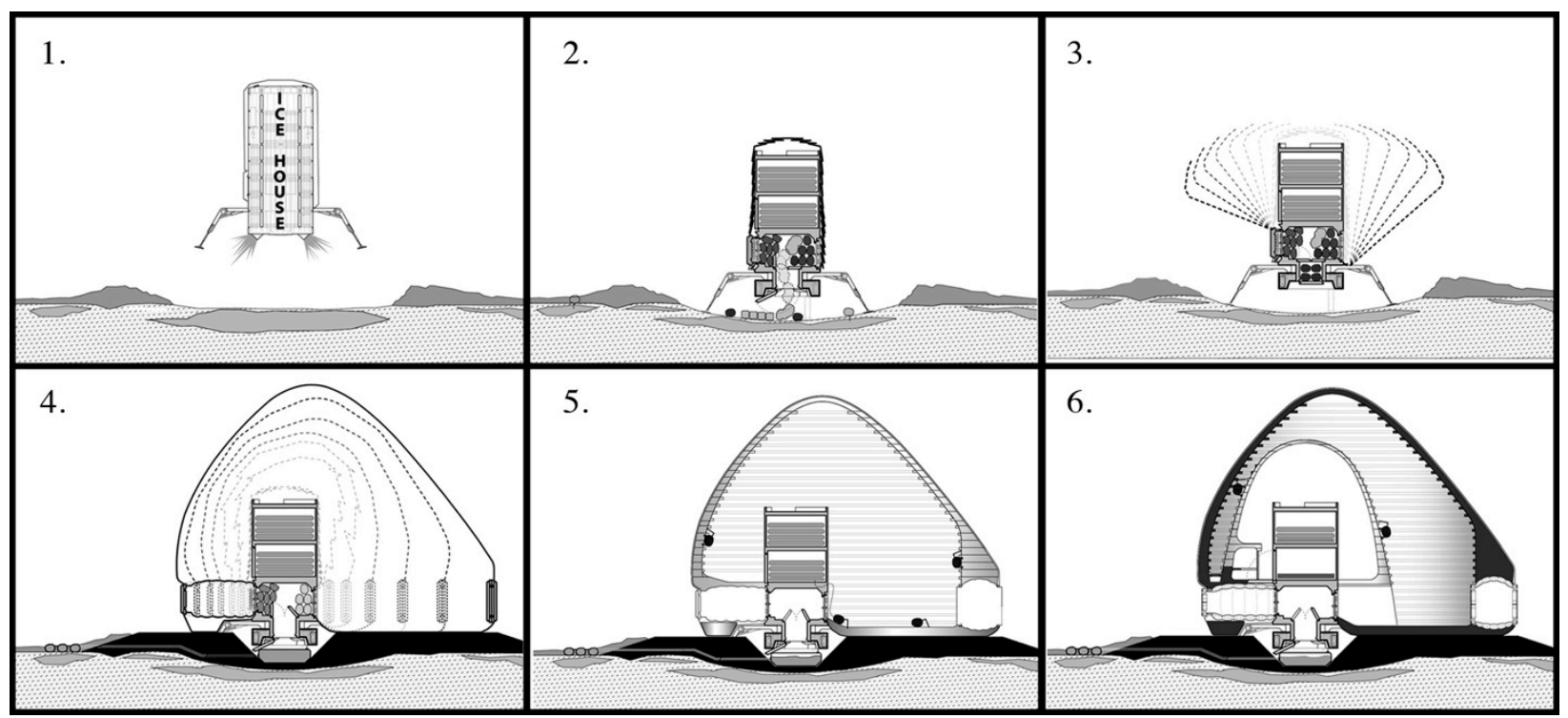

Figure 7. Concept of Operations and Deployment (1) Vertical Landing (2) Release of robotic water extraction (3-4) Deployment of Pressure Membrane (5-6) Interior Printing with climbing robotics. 


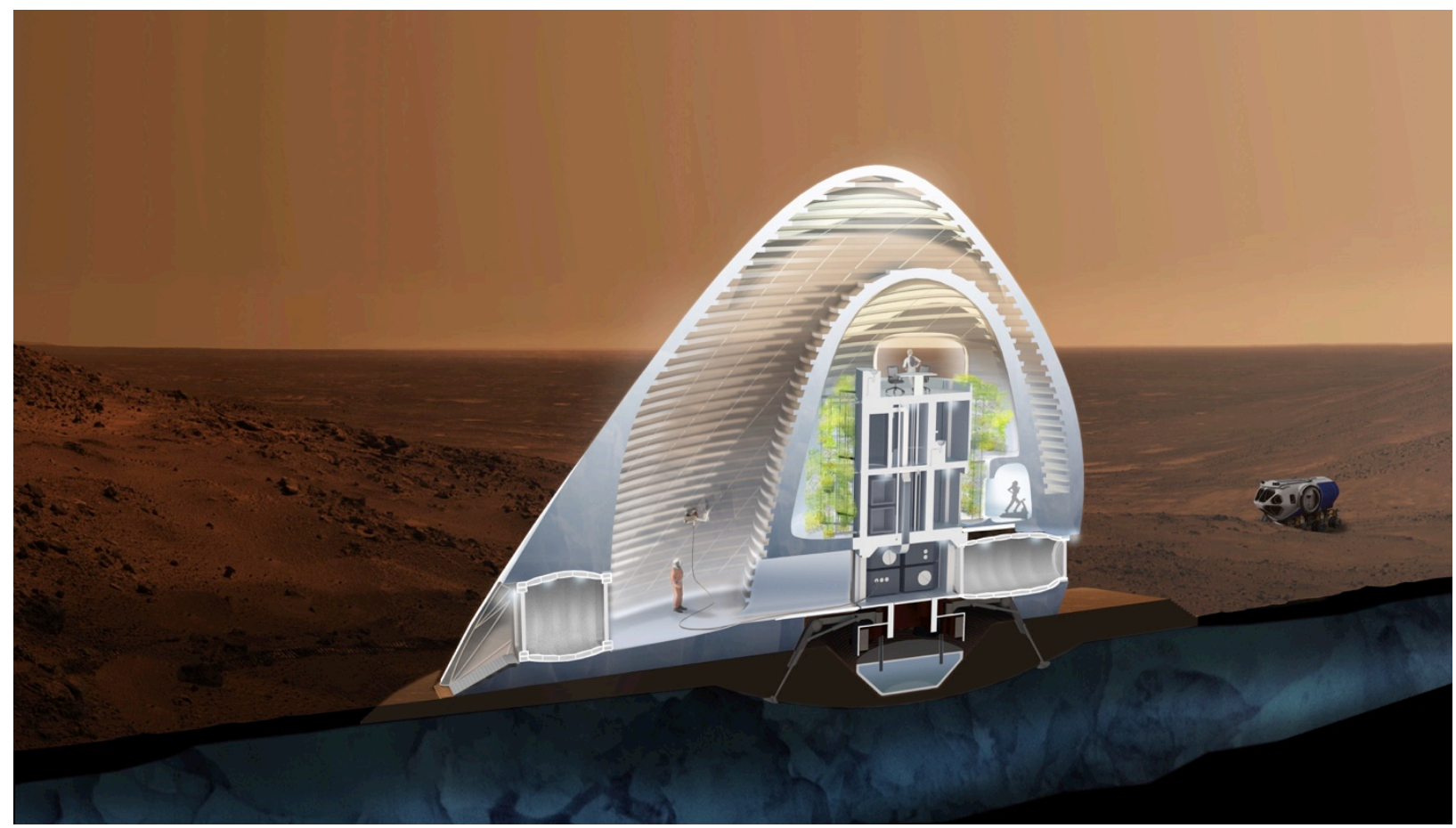

Figure 8. Sectional view through the interior revealing double wall condition, vertical garden, and interstitial "yard."

\section{Architectural Concept}

Understanding that the conceptual benefits of $3 D$ printing include the possibilities of not simply printing "walls," "roofs," and "floors" but in fact printing the entire shapes and forms of the spaces themselves, the interior volume of ice is printed as a series of conceptually excavated or "hollowed-out" programmatic spaces to form the walls and divisions of the habitat volume. Mars Ice House is envisioned as a series of nested translucent "hollowed out" domes enclosed by a transparent ETFE or similar membrane. This membrane establishes a pressure boundary that prevents the ice from sublimating and manages the cyclical relationship between the exchange and transfer production of oxygen and $\mathrm{CO}_{2}$.

Thermally separated from the habitat interior, the occupiable "front yard" pocket just inside the outer shell provides a truly unique protected neutral zone that is not entirely interior or exterior; it enables the astronauts to experience the "outside" without ever donning an EVA suit. This interstitial zone space demonstrates a new and liberating definition of living extra-terrestrially - one that celebrates the novelty and wonder of living on Mars. The lander's yard exists where a secondary, semi-independent shell of ice peels away from the exterior shell. The protective redundancy of the double skin creates two layers of space between the ETFE membrane and the lander, which while sharing a common pressure boundary, also creates a distinct temperature and air make-up zone. The secondary layer of ice, lined with insulation, can be thickened and thinned to control translucency, creating a bespoke habitat and layout interior experience and still capable of being customized through adaptable printing to any number of functional constructions and program configurations

\section{A. Siting}

On Mars, water is abundant in the higher and lower latitudes. ${ }^{6}$ Site selection was determined by a multitude of parameters, including balancing access to a shallow ice table from the surface (within $20 \mathrm{~cm}-1 \mathrm{~m}$ ), with temperatures that remain below freezing throughout the Martian year. Considering requisites such as relatively gentle slopes and soft terrain for construction, as well as the desire for maximum possible solar exposure, an area on the northern flanks of Alba Mons was selected, to be sited somewhere between $45 \mathrm{~N}-50 \mathrm{~N}$ latitude and $230 \mathrm{E}-270 \mathrm{E}$ longitude. The volcano display flanks slopes of 2.5-5, allowing us to take advantage of the colder temperatures within the polar regions, while remaining as far south as the predicted distribution of ice permits for solar exposure. While these requirements are optimized for construction, they are also ideal for views at higher altitudes and extended geological and scientific exploration, given its location on a volcanic plateau. 


\section{B. Structural}

As previously discussed, most in-situ 3D printing concepts rely on a supplemental enclosure to serve as a pressure vessel. The Mars Ice House design also calls for the containment of air by a reinforced pressure membrane brought from earth on the exterior of the habitat (rather than interior). Also differing from typical strategies for inflatables with an internal bladder and structural restraint layer, models investigating stress indicate the membrane to be capable of supporting the overall load, leaving the ice to primarily support it's own gravitational load. Internal pressure was derived from that aboard the space shuttle at $70 \mathrm{kPA}$.

Primarily formally a catenary dome, the design of the ice house is capable of not only supporting it's own weight but also capable of standing gravitationally during the level by level deposition process. Starting with walls at a thickness of $0.6 \mathrm{~m}$ and tapering to $6 \mathrm{~cm}$, the ice is fully self-supporting.

\section{Thermal}

Of particular importance in the concept design of a structure made with ice is the thermal control of both the interior habitat as well as the maintenance of subfreezing temperatures for the ice itself. The nested concept of describes a wall section in which the outer layers of ice remain at Mars temperatures or a maximum of $0^{\circ} \mathrm{C}$ with the interior at room temperature near $20^{\circ} \mathrm{C}$.

It is anticipated that the interior will be heated largely through mechanical systems, but will also experience heat gain from the sensible and latent heat of the occupants within, as well as some solar gain through the translucent structure. There will be a need to vent or radiate heat to the exterior without transmittance through the ice wall. A venting system through the lander is possible, as well as the storage of thermal heat in water storage units already supposed for the printing mechanism.

To temper the heat between the lander and habitable areas, a vertical "greenhouse" is supposed, surrounding the interior core capable of absorbing, and re-distributing some heat to the habitation spaces.

To prevent heat from the habitable areas from reaching the ice layer, a translucent hydrophobic aerogel layer ${ }^{11}$ with light transmittance of $66 \%$ between the inner ice shell and the inhabited programmatic spaces could be used to ensure thermal comfort. A

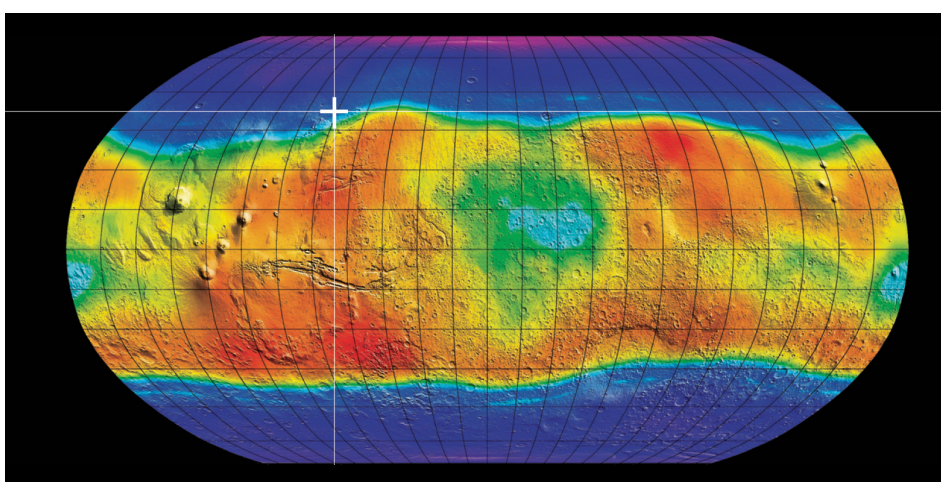

Figure 9. Map showing hydrogen distribution. 2001 Mars Odyssey Gamma Ray Spectrometer.

Finite Element Model of Maximum Stress in Dyneema ${ }^{\circ}$ Membrane under $70 \mathrm{kPa}$ Internal Pressure

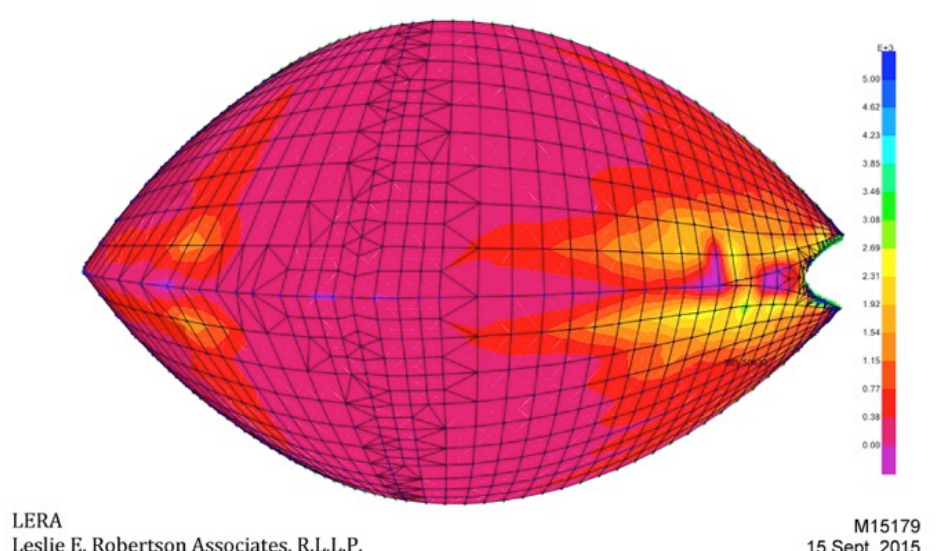

Leslie E. Robertson Associates, R.L.L.P.

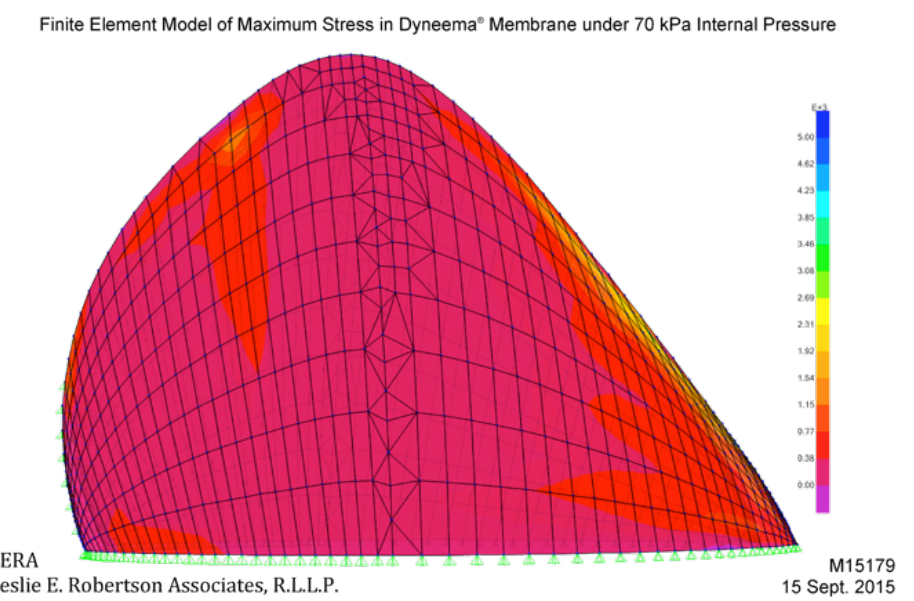

Leslie E. Robertson Associates, R.L.L.P.

15 Sept. 2015

Figure 10. Finite element analysis model of stress in the pressure membrane under $70 \mathrm{kPA}$ internal pressure. Done for Mars Ice House by structural engineering firm Leslie E. Robertson Associates. 


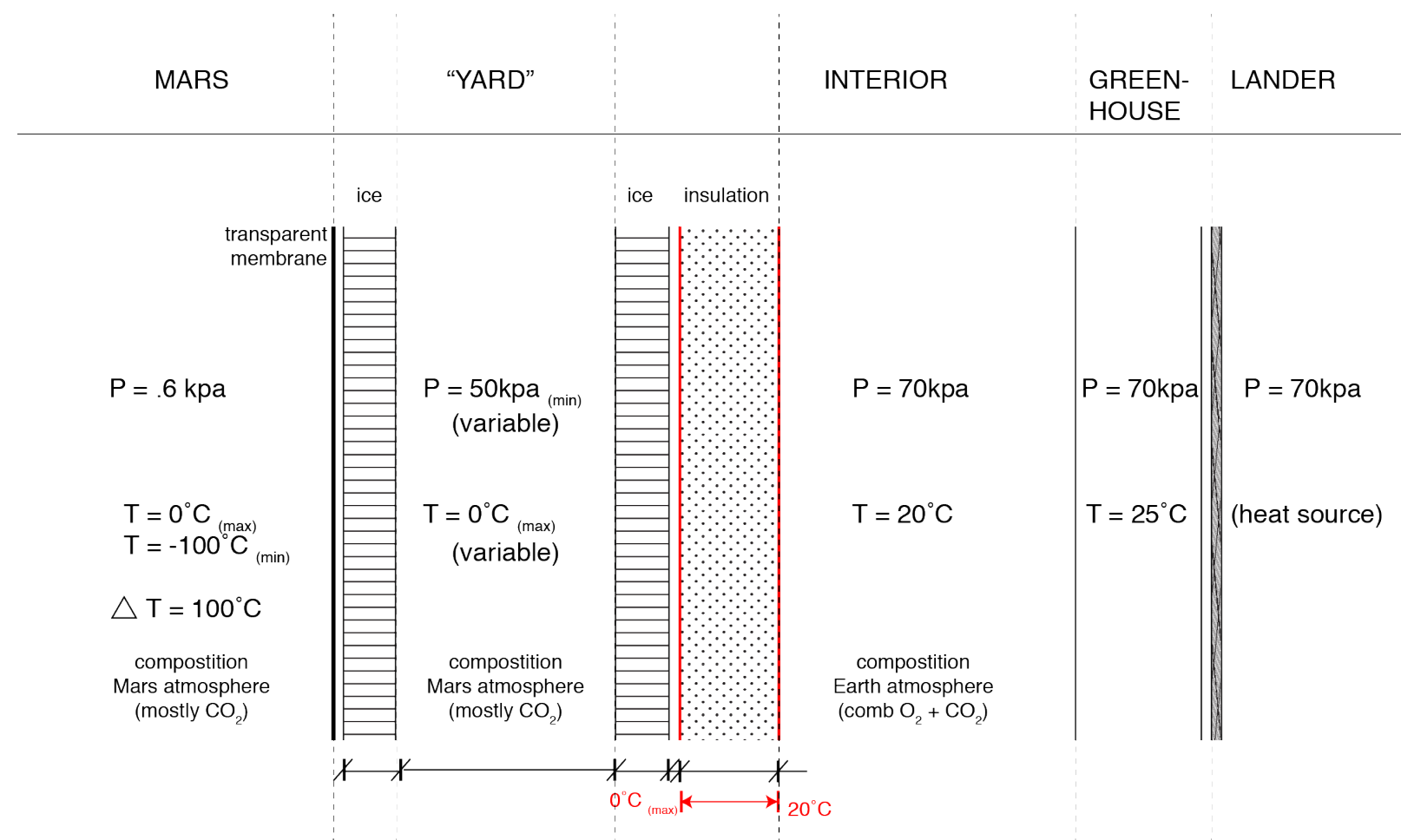

Figure 11. Conceptual Wall Section indicating the layered composition and variable pressure and temperature in each zone.

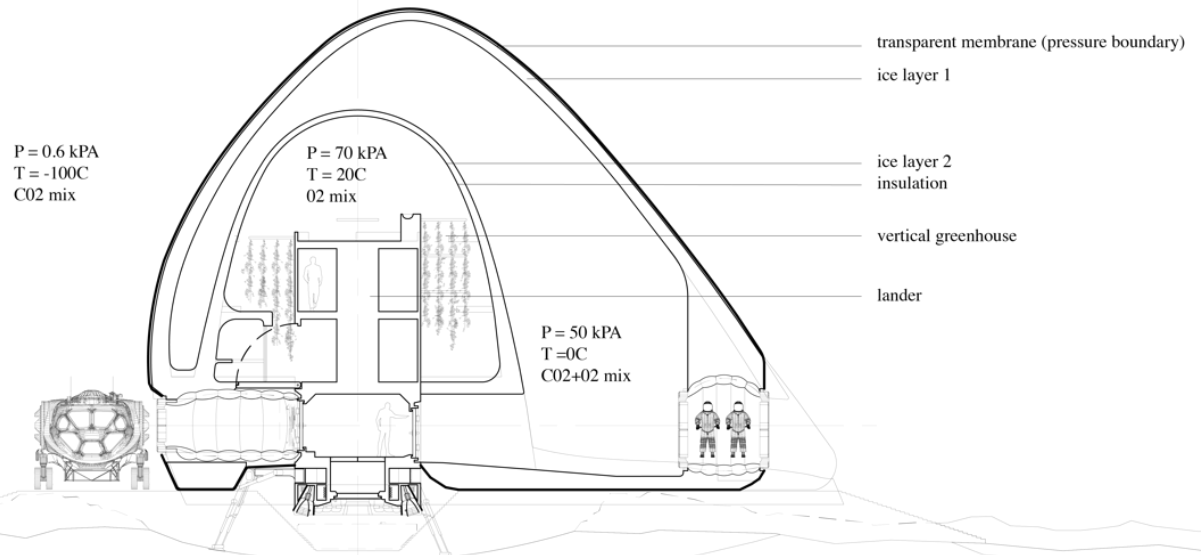

Figure 12. Conceptual Habitat Section indicating the layered composition and variable pressure and temperature in each zone.

porous substance, 99.8 percent empty space by volume, this additional lightweight material brought from Earth, could serves an efficient air gap to create the necessary thermal break as well as possibly retain the translucent nature of the habitat.

Due to the nature of the 3D printed spaces, this insulation layer is also assumed to be 3D printed. The ability for aerogels to be additively manufactured is currently under investigation and several tests with graphine aerogels have been successful at Kansas State University and the University of Buffalo. ${ }^{21}$ Such an insulating layer enables the inner volume to achieve habitable temperatures without melting the ice structure beyond. 
Of course in precedent examples on earth ice and snow itself has been used as an insulator. Given the ability to vent enough heat to the exterior or store it, there could be potential for other ways of distinguishing between drier warmer interior layers and colder but habitable exterior layers. Further research is needed to conduct thorough energy models.

\section{Light}

The translucent properties of the material are expected to let natural light from solar radiation in the visible spectrum to flood into the habitat, in areas where ice is thicker, even reflecting and multiplying light inside in the double walled interior.

The verticality of the habitat itself is meant to increase the area of visible light entering at lower angles in the northern hemisphere.

\section{E. Habitation / Interior Spaces \& Program}

Habitation in the Mars Ice House is a relationship between the hard mechanical services housed in the landed deployed from Earth, and the "space" created by the 3D printed structure. The lander serves as the central backbone through which all services including water, electrical, and ECLSS function run, leaving the habitat space to be simply functional human spatial volumes.

1) The Lander

The vertically oriented lander inherits the likely orientation of the crew's (MTV) Transit Habitat $^{12}$ to ease the crew's adjustment to life on the Martian surface. The habitat's stacked levels organize core programs by activity within the lander, introducing a spectrum of private to communal interior spaces. Interior efficiency creates sizable storage pockets at the base of the lander to house the bots as well as the four Environmental Control and Life Support Systems (ECLSS).

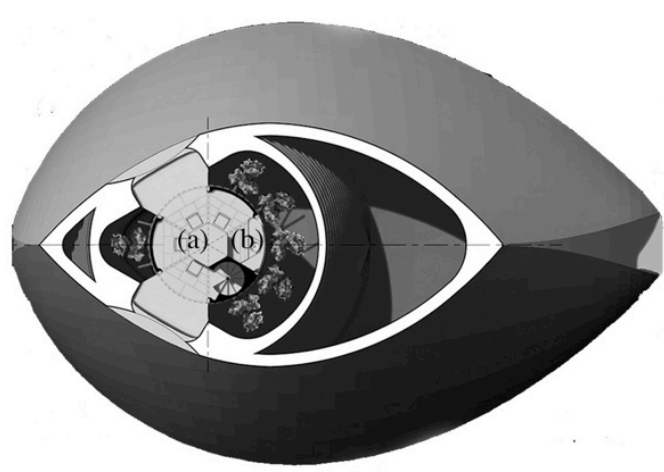

LEVEL 4

(a) Ward Room/Galley

(b) Food Prep

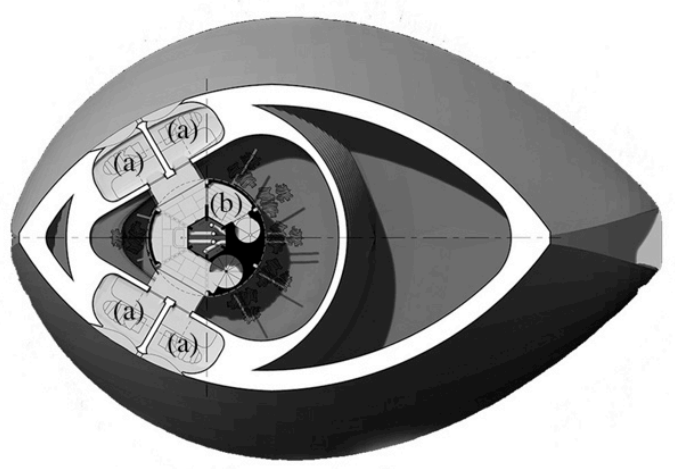

LEVEL 3

(a) Crew Quarters

(b) Shower + Bath

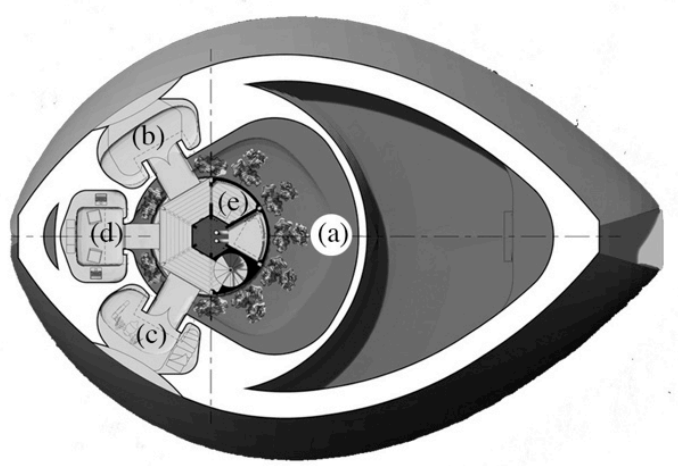

LEVEL 2

(a) Greenhouse

(b) Laboratory

(c) Medical

(d) Work Rooms

(e) Bath

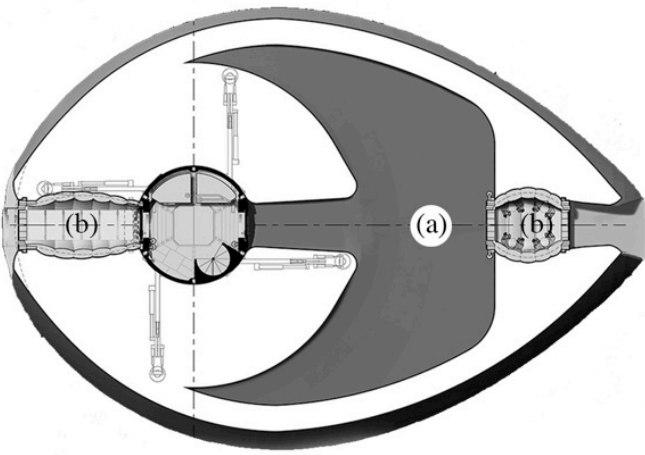

LEVEL 2

(a) "Yard"

(b) Airlocks

Figure 13. Architectural Plans showing concept of hollowed out spaces and nested layers (an interstitial "yard," greenhouse, and central lander. 
2) Bridges

Once the lander has deployed the inflatable ETFE membrane, pre-fabricated bridges unfold from within the lander, creating 'pockets' for inserted program. A spiral stair at the core of the lander provides circulation to the upper levels of the habitat.

3) Rooms

The curvaceous form of the rooms creates an illusion of cycloramic space, enhancing perceptions of boundlessness, making a small space seem quite large.

4) Windows

Though the habitat is meant to be translucent there is still a desire to incorporate true transparency. Where the ice shell thins, large ETFE inflatable windows filled with an appropriate radiation shielding gas such ah Hydrogen $(\mathrm{H})$ or Helium $(\mathrm{He})$ further expand the perceived volume and frame views into the landscape. Together, these features enable both collective and private opportunities to contemplate the vista of the extraordinary Martian terrain.

5) Interior Garden

Between the lander core and the ice interior, verdant plant life surrounds the inhabitants. The vertically growing hydroponic gardens disrupt the monotony of Mars' landscape while also supplementing the crew's food and oxygen. The gardens enable the growth of experimental consumable produce, and their placement between programmatic zones offers the crew contact with natural plant life and colors throughout their daily scheduled activities. The resulting variegated "dappled" light effects benefit the crew's psychological and mental well-being and the 'yard' provides space in which to vent any excess oxygen produced.

6) The Yard

The interstitial space between the domes provides an area that while cold, is still pressurized, allowing for freedom of movement without the need for the EVA suit. The architectural intention was to provide a redundant layer of external protection and internal venting and overflow while simultaneously making an abstract inspirational space that extends the habitable volume.

7) Program Distribution

The first level of the habitat consists of a laboratory space, a medical and exercise facility, as well as a small northern-oriented contemplation / meditation room that boasts a window to the exterior. The second level of the habitat is devoted to southern northwest-oriented sleeping quarters, as well as the first (of two) hygiene units. Despite the fact. Although our design provides each crewmember with individual sleeping compartments complete with visual and acoustical privacy, the layout of the units themselves counters potential crew isolation by spatially encouraging socialization between crewmembers. The third (and final) uppermost level offers an open domed loft wardroom with a communal table located at its center. A counter height galley contains pantry, sink and food preparation station, in addition to the secondary hygiene unit, affording the astronauts a light filled 360 panoramic domed space.

\section{Conclusion}

Development continues on earth for traditional methods of depositing materials for additive manufacturing. Certainly we will see from terrestrial pursuits the continued feasibility of large scale construction using 3D printing methods and the development of the appropriate robotic mobility as well as material investigation and deposition tools.

The concept of building with $\mathrm{H}_{2} \mathrm{O}$, despite its long history and clear benefits in radiation protection, remains a novelty on Earth and it's potential uses for space still untested. The notion of constructing with such a simple material, and even possible low-tech construction techniques using the basic physics of phase change is what makes the project concept both exciting, and also possibly unnerving. Further research is required in the development of the printing nozzle of the right pressure, temperature, and velocity to create accurate prints with water but the research is underway, also for terrestrial pursuits notably in arctic climates or where temporary structures would be required. Its ability to be used in full-scale construction should track with those of similar materials in additive manufacturing. The alternative method mentioned for sublimation of gas directly onto the interior of a surface as a potentially lower tech solution should also be pursued. For space applications, testing of ice within a pressure membrane at Mars 
similar temperature and pressure ranges is a necessary next step as well as the undertaking of energy modeling and analysis to determine appropriate levels of insulation and heat rejection needs.

The concept design of the Mars Ice House demonstrated material possibilities but also a design methodology resulting in the consideration of new possibilities and ideas for human space exploration. As the overall winner in NASA/America Makes' Centennial Challenge one can only assume that the originality or vision of the concept was perceived of as a value. In continuing to pursue ideas for human habitats, a design methodology rooted in equating technical, environmental, and structural concerns, within the context of a human based mission provides a suggestion for new approaches to design methods. The Mars Ice House, composing itself of an interdisciplinary team of subject matter experts, lead by architects, continues to challenge traditional design approaches by considering fundamental physics, re-visiting design requirements, and organizing behind an objective consistent with a human centered mission.

Given the restrictions and constraints of spaceflight, new requirements or a re-visiting of requirements is often required to be backed by extensive scientific research. While the effects of special organization, lighting, scale, and form are often attributed with having an effect on human psychology and wellbeing, scientific and psychological studies may not be as appropriate a tool for the parsing of design strategies for humans, as long term historic and contextual architectural experience and example.

\section{Acknowledgments}

With special thanks to a host of subject matter experts who acted in a consulting basis including:

Jared W. G. Atkinson; Planetary Geophysics, MIT. Specialist in the physical and mechanical characteristics of icy regolith at cold extraterrestrial temperatures.

Maria Banks PhD; Geology and Planetary Scientist, Planetary Sciences Institute. Principal research in ice-related erosional and depositional landforms on Earth \& Mars.

Kim Binstead PhD; Associate Professor at ICS Dept, University of Hawaii. Principal Investigator for the Hawaii Isolation Experiment (HI-SEAS, 2015).

Eric Barnett, Research Associate (ret.) School of Architecture, McGill University

Casey J. Handmer PhD; Theoretical Astrophysics, California Institute of Technology.

Stefan Harsan Farr; Engineer, Software Architect.

Jeffrey H. Hoffman PhD; Professor of Practice of Aerospace Engineering, MIT Department of Aeronautics and Astronautics.

Norbert Koemle PhD; Geophysics, Austrian Academy of Sciences, Space Research Institute

Petr Novikov; Founder of DOM: Robotically assembled structures. Creator of Stone Spray 3d printing technology, Institute for Advanced Architecture of Catalonia.

Javier Roa; Orbital Mechanics/Aerospace Engineering, Technical University of Madrid. Current JPL Research Affiliate specializing in regularized formulations of orbital motion.

Pavlo Rudakevych; Roboticist, Aeronautical Engineer at iRobot. Experience with satellite launches, robotics with a 3d-printer patent pending.

Markus Scheucher; Physics and Space Sciences, Karl Franzens University of Graz

Pieter Sijpkes, Associate Professor (ret.) School of Architecture, McGill University

Dr. Ron Turner, ANSER Distinguished Analyst

Lawrence W. Townsend PhD, Chancellor's Professor of Nuclear Engineering, University of Tennessee 


\section{References}

${ }^{1}$ Ashbe, K. Fundamental Principles of Fiber Reinforced Composites. Lancaster: Technomic Publishing: 1993

${ }^{2}$ Buratti, C., Moretti, E.. "Experimental performance evaluation of aerogel glazing systems,” Applied Energy, Vol 97 (2012): 430-437

${ }^{3}$ Czeisler, C.A., Dijk, D.J., Neri, D.E., Wyatt, J.K., Ronda, J.M., Riel, E., Cecco, A.R., Hughes,R.J., “Sleep, Circadian Rhythms, and Performance During Space Shuttle Missions." The Neurolab Spacelab Mission: Neuroscience Research in Space: p 211-221.

${ }^{4}$ Edwards, L. Torcellini, P. A Literature Review of the Effects of Natural Light on Building Occupants. [Golden, National Renewable Energy Laboratory] 2002.

${ }^{5}$ Davilla, A.F., Willson, D., Coates, J.D., McKay, C.P., "Perchlorate on Mars: a chemical hazard and a resource for humans." International Journal of Astrobiology, Oct 2013.

${ }^{6}$ Feldman, W.C., "Global Distribution of near-surface hydrogen on Mars.” Journal of Geophysical Research, Vol 109 (2004)

${ }^{7}$ Haines, R. F., "Windows: Their importance and Function in Confining Environments." From Antartica to Outer Space: Life in Isolation and Confinement. Springer, New York, 1991. p349-358.

${ }^{8}$ Hubbard GS, Naderi FM, and Garvin JB. "Following the water, the new program for Mars exploration." Acta Astronaut, VO1 51 (2002): 337-350.

${ }^{9}$ Kennedy, K.. "Lessons from Transhab," AIAA Space Architecture Symposium, Oct 2002.

${ }^{10}$ Lange, M.A., Ahrens, T.J.. "The dynamic tensile strength of ice and ice-silicate mixtures," Journal of Geophysical Research, Vol 88 (1983): 1197-1208.

${ }^{11}$ Prockter, L.M. "Ice in the Solar System,” Johns Hopkins Applied Technical Digest, Vol 26 (2005): 175-188.

${ }^{12}$ Rapp, D., "Radiation Effects and Sheilding Requirements in Human Missions to the Moon and Mars," The International Journal of Mars Science and Exploration [online journal], Mars 2, 46-71, 2006; doi:10.1555/mars.2006.0004 [cited 29 September 2006].

${ }^{13}$ Simonsen, L.C.;Nealy, J.E., "Radiation protection for human missions to the Moon and Mars." NASA Technical Report: N91-17999 (1991)

${ }^{14}$ Sijpkes, P., "The architecture of phase change at McGill.” Leadership in Architectural Research (2009): 241

${ }^{15}$ Warren, S., "Visible and near-ultraviolet absorption spectrum of ice from transmission of solar radiation into snow," Applied Optics 45 (2006): 5320-5334

${ }^{16}$ Wilson, J.M., Miller, J., Konradi, A., Cucinotta, F.A., (ed) "Sheilding Strategies for Human Space Exploration," NASA Conference Publication, 3360, NASA, 1997

${ }^{17}$ Drake, B.G. (ed). Human Exploration of Mars Design Reference Architecture 5.0. NASA-SP-2009-566

${ }^{18}$ Stuster, J. (ed). Bold Endeavors: Lessons from Polar and Space Exploration. Naval Institute Press, 2001.

${ }^{19}$ Adams, J.H.. (ed). Revolutionay Concepts of Radiation Shielding for Human Exploration of Space . NASA/TM-2005213688

${ }^{20}$ Hassle, D., et al., "Mars’ Surface Radiation Environment Measured with the Mars Science Laboratory's Curiosity Rover." Science. Vol 343 (Jan 2014): 1244797.

${ }^{21}$ Zangh, Q., et al., “3D Printing of Graphine Aerogels.” Small. Vol 12, Issue 13 (April 2016): 1702-1708. 